\title{
Study on the Language Strategies of Network Marketing to Women: Taking Taobao Style as an Example
}

\author{
Yudan Yang $^{1} \&$ Siyao Huang ${ }^{1}$ \\ ${ }^{1}$ School of Humanities, Jinan University, Zhuhai, China \\ Correspondence: Yudan Yang, School of Humanities, Jinan University, Zhuhai, China. E-mail: \\ yyd506@sohu.com
}

Received: January 28, 2015 Accepted: March 9, 2015 Online Published: March 16, 2015

doi:10.5539/ass.v11n7p43 URL: http://dx.doi.org/10.5539/ass.v11n7p43

\begin{abstract}
It is necessary to communicate with women according to the female psychology to network marketing success. Taobao style is a dialogue between buyer and seller when they are doing business in Taobao e-shopping. By analyzing its language characteristics, where and how people use it, this paper points out that Taobao style is a kind of feminine language strategy which can be used in sales, after sale service and evaluation management. It can help us in creating a good image of seller and in reducing disputes in the trading market.
\end{abstract}

Keywords: network, female marketing, language strategy, Taobao style

\section{Introduction}

With a strong purchasing power, Women are the main force of online consumption. MasterCard Worldwide has predicted that the spending power of Chinese women will keep growing and increase from 330 billion dollar in 2005 to 525 billion dollar by 2015 (Ernst \& Young, 2007). Meanwhile, it's worth noting that women varies a lot from men in many areas, including decision-making, aesthetic, user experience as well as point of focus. They tend to be more indecisive and focus more on shopping experience and details. Therefore, it's necessary to communicate with women according to the female psychology and e-shopping environment to female marketing success.

\section{Changes of Female Marketing Accompanied by the Development of Internet}

Female Marketing is a whole set of marketing activities that being involved in, organized or engaged in by women, it emphasis the dominant role of women in these economic activities (Chen \& Zheng, 2008). As the network era has come, some important changes are taking place in the environment of Female marketing.

Network has brought up integrated marketing channels, which benefits women to make fully comparison between stores or goods before their consumption. The integration of marketing channels is in the following aspects mainly: region, time, information of goods and media integration. Firstly, the distributed architecture of network renders it as a cross-regional communication way. Enterprises could put products' information on the internet while consumers could shop at home and anywhere they have access to the internet. Secondly, network, which brings up 24-hour opening online shop, has largely narrowed the links between shopping and time as well as broken up an orthodox opinion that we could only shop at the working hours. Thirdly, with vast shopping information, network makes it rather convenient for us to seek and compare different goods' information as well as the condition about after-sales service. Fourthly, network is just like a huge database that contains information from television, broadcasting, magazine, forum, blog and social medium; it offers comprehensive marketing channels for enterprises to sell their products. It also makes it possible for consumer to get this information through a search engine.

Network makes shopping separated from product experience; the personalized demand of products could be satisfied. On one side, due to the isolation characteristic of the Internet, buyer and seller are in the isolate state in network marketing. Therefore, instead of letting the consumers touch the products directly, seller could only trigger buyer's interest by literal and photographic description of product information. As a result, the rendering of digital information and communication determines the result of network marketing to a large extent. On the other side, personalized needs of products used to be submerged in the industrialized and standardized batch production and could not be satisfied. But nowadays seller could communicate with customers one-to-one easily 
on the internet, in this way customers could get customized special commodity and service according to their own individual demand. In the Internet era, various products begin to appear in front of consumers and the supply of products has a trend of diversification.

Communication skills and techniques has become the key to successful network marketing. Due to the individuality characteristic of the internet, seller could achieve interactive conversation with customers at any time, thus achieve interactive marketing. Firstly, seller could have a real-time synchronized conversation with customer via web pages or communication software. They can also have an asynchronous man-machine conversation through electronic bulletin boards, E-mail and so on to let the information reach individual customers. What's more, network technology can collect and record the information of consumer behavior, including personal data, details of buying record, product evaluation, etc. These kinds of data could be highly valuable references for the seller to communicate with its customer next time. In addition, network can also provide instant feedback, including after-sales problem and sending out a follow-up promotion news etc. To sum up, the openness characteristic of information on the Internet determines that the public praise is one of important process of network marketing. The Internet is a highly open place where consumers can create, spread and easily get some information about products. Public praise, also named word-of-mouth, has already become an important factor in the consumer's decision-making process.

\section{Taobao Style Is a Kind of Feminine Language Strategy}

Taobao style, an important language style in network marketing since around the end of 2010, is a dialogue between buyer and seller when they are doing business in Taobao e-shopping. Nowadays, Taobao style is not only used on various Internet trading platforms, but also used in daily written and oral interpersonal communication.

By doing both qualitative and quantitative analysis about the linguistic characteristic, pragmatics environment and use condition of Taobao style, this research found out that the reason of Taobao style being prolonged popular in both network marketing and real society lies in its feminine characteristic, which is a kind of feminine language communication strategy that fits network environment well.

\subsection{Linguistic Characteristic: Friendly, Concise and Colloquial}

Martin Joos divides language style into five types as follows: polite, formal, consulting, casual and friendly style. The friendly style, which is used to communicate with some people with close relationship, is highly abbreviated and sometimes accompanied with some slangs (Zhu, 1992). The main feature of Taobao style are concluded as follows: It used Qin (which means dear in English) to call others; It use a great deal of modal particles such as "O", "Ah", "La", "Ba", "Ha", "Ne", etc; It uses a lot of short sentences and single-word sentences; It use various network emoticons, question marks and exclamation marks, which makes it have a strong emotion and obvious colloquial tendency ( $\mathrm{Lu}, 2013)$.

"Qin", the abbreviation of "Qin Ai De" (which means "dear" in English), are mostly used between some people with close relationship, especially some young women who will use it to call some friends, no matter with same sex or not. By imitating the conversation style of some close people, Taobao style can help people to call others easily on the Internet, where we don't know other's gender and age. Such a language strategy enables seller to build up a closer friendship with their customers thus customers will not alienate them.

Taobao style uses a great deal of modal particles, which can express personal emotion in a more vivid way, such as enthusiasm, surprise, amaze, loveliness and pity. This kind of emotion can create a good image of seller and reduce disputes when both bargaining and rejection. Among all the modal particles being used in Taobao style, "O" has been used most frequently. "O", implying a kind of feminine cutesy, is a preferred tone of voice of women. By using such a feminine word speakers could be felt like a girl so that others may be easier to give way in a bargaining about price or post-free (Yang, 2014).

Taobao style uses a lot of short sentences and single-word sentences, such as “Bao You O” (“包邮哦” means post-free in English), “Chao Zan” (“超赞” means a complimentary like "good” in English). The substance of Taobao style is a spoken language. With great deal of network emoticons and abbreviation words like "Xiao Er" (“小二” means "shop assistants" in English), "YY" (means "clothes" in English), the colloquial characteristic of Taobao style is rather obvious.

\subsection{Pragmatic Environment: Both Online Shopping and Daily Interpersonal Communication}

This research found that the use of Taobao style mostly happens in an online shopping occasion. Besides, its use in network communication takes the second place, and its use in daily interpersonal communication takes the third place. Since the applied occasion and communication context are so close to our social life, it's no 
wondering Taobao style have a fame much higher than other network language style, thus could be popular for a longer time and in a wider area.

Firstly, Taobao style is mainly applied in online shopping occasion. While most network popular styles have neither fixed applied occasion nor specific user, Taobao style specialized in online shopping occasion and its main user are online shopper and seller. In other words, Taobao style can satisfy the need of both network seller and buyer, and that's the root cause of why Taobao style can be so popular in a wide scale. In the meantime, being widely used social networking like QQ, MSN and Weibo comments; Taobao style becomes to be widely used and takes up an increasingly important place in network interpersonal communication.

Secondly, Taobao style is a powerful communication tool which could enhance intimacy and shorten the interpersonal psychological distance. The function of network language style can be divided into following five aspects mainly: entertaining, mockery of the reality, self-expression, venting and communication. Entertaining refers to the language style which is not original but very interesting, hence everyone initially imitate the way they talk to entertain themselves, such as Zhen Huan style (originate from TV serious Legend of concubine Zhen Huan), Zhiyin style, Qiongyao style. Mockery of reality refers to some language type on the Internet satirize the reality in an ironic way, for instance, netizen use Cheng Yao style, which originate from the headmaster of Beijing University, to satirize some immoral behavior. Self-expression refers to people use some particular form of dialogue to look within themselves, analyze themselves as well as express their own attitudes and values, Vancl style is one typical case. Venting refers to release work pressure and express emotion like angry, apology, surprise, grumble, and discontent and so on, such as the Roaring genre. Communication refers to a type of network language that point out to communicate with others fluently and without dispute or estrangement, just like Taobao style.

As for pragmatic function, as an intimate appellation, "Qin" can shorten both psychological and social distance between both sides. And the use of modal particle "O" conforms with politeness policy thus benefits a smoothly communication (Shi, 2012). With Taobao style, it seems that we could see a smile woman even through network, where we are all anonymous in fact. Additionally, Taobao style can shorten the interpersonal distance and bring up a closer relationship. All of these contribute to the widely use of Taobao style in interpersonal communication.

\subsection{Use Condition: Women Are in the Majority of Taobao Style's Users, with Positive Evaluation}

The research methods used in this study were questionnaire and personal in-depth interview, the aim is to find out current use condition about Taobao style's user, use range, use habits, use psychology and use influence. The questionnaires were posted on the Internet on July, 2014. According to 409 valid questionnaires, the survey results are as follows:

\subsubsection{The Majority of Taobao Style Is Middle-Aged Women Who Often Shop Online}

The survey results are as follows: $23.6 \%$ of women consumers often use Taobao style and $49.6 \%$ of women consumers sometimes use it. While only $15 \%$ of men consumers often use it and $39 \%$ of men consumers sometimes use it. It's obvious that compared with men, women tend to use Taobao style more frequently. As for users' age, among people who often use Taobao style, people around 30-39 years old take up the largest percentage, after that is 20-29 years old. Among people who sometimes use Taobao style, people around 40-49 ranking first and 30-39 ranking second. To sum up, people around 30-39 years old take the largest percentage in the users of Taobao style. As for the cost on the online-shopping, respondents who spend more on the online-shopping tend to be more likely to use Taobao style.

3.3.2 Users Evaluate Taobao Style Positively; They Use It for the Reason that It Can Increase Intimacy. Women Tend to Make Greater Use of Taobao Style

In order to figure out the impression of Taobao style, this research adopts sequencing multiple-choice in the questionnaire. We ordered the weighted scores which have been evaluated as follows: "Kind" scores 5.53, "Cute" scores 4.25, "Casual" scores 3, "Polite" scores 2.82, "Girlie" scores 2.8, "Gentle" scores 2.3, "Personality" scores 1.32, "New" scores 1.31, "Tacky" scores 0.67 , and "Disgusting" scores 0.28 . The higher the score is, the topper this adjective word ranks. Thus it can be concluded that impressions of Taobao style are tend to positive and affirmative, most people consider it as a kind, cute, as well as polite language style, while only very small number of people consider it as disgusting and negative.

Another question aims at figuring out the reason of the usage of Taobao style proves that people use this language style in order to get closer to other speakers as well as to show their humor and kindness. The results are as follows: $68.4 \%$ of respondents say they use it to show their kindness and hope to get closer to others; $29.7 \%$ 
of respondents want to make conversation more smoothly and conveniently via Taobao style; $23.4 \%$ just do it to conform; $19.3 \%$ of respondents use it because they consider it new and fashionable.

Additionally, this research also found out online buyer's preference towards Taobao style. When doing online shopping, $12.55 \%$ of female shoppers love to have direct communication with seller very much, $36.44 \%$ of female shopper like to have direct communication with seller, $38 \%$ do not care much about this. In the greeting process of online communication, 53.9\% of shopper prefer to receive a greeting sentence like "Hello Qin, Can I help you" (where Qin have a close meaning to dear), 10.8\% of shopper prefer to receive a greeting sentence like "Qin ", and the other 35.3\% percentage of shopper prefer to receive a greeting sentence like "Hello". In the bargaining process of online communication, $69 \%$ of shopper prefer to receive a mild and patient sentence like "Qin Since all the photos are based on the real products and best quality, the price cannot be lower", $26 \%$ of shopper prefer to accept a rejection like "Please understand that we just have small margin therefore there cannot be bargaining", and only 5\% think they can accept a rejection like "No bargain". To sum up, the composite score of Taobao style is 3.82 out of 5.00, which indicates that online shopper hold a positive attitude toward Taobao style. By looking into the statistics more carefully, you can find out that the composite score of Taobao style from women respondents is 4.01 out of 5.00, while that from men respondents scores only 3.52 out of 5.00. Hence we can draw a conclusion that female online shopper holds a stronger preference towards Taobao style than male online shopper.

\section{Revelation of Marketing Drawn from the Popularity of Taobao Style}

Helene Cixous pointed out that there was a widely existed duality opposition between men and women. While men were considered as rational, understandable, centralized, monistic and left-brain thinking, women were considered as emotional, sensible, decentralized, multi-dimensional and right-brain thinking. Though we used to think the society is dominated by men, we have to change our mind as the women is gaining more and more important status in network era. Women are the main force of online shopping in china as well as the most frequent users of worldwide social networking. Meanwhile their way of thinking is highly consistent with that of the Internet. Therefore women's psychology and behavior could have an important impact on the development of network marketing. The prolonged popularity of Taobao style has a substantial psychological reason which can give us some vital revelations.

\subsection{Network Marketing Should Attach Great Importance to the Psychological and Communicative Feature of Women}

Firstly, seller should offer detailed, various and nice-looking information when they introduce their products to online shopper. Women are a perfectionist and tend to be selective when they shop. With a pursuit of beauty, they could be highly sensible to anything being related to visual element, including the appearance, shape and display way of products. Such way of thinking could easily leads to impulse buying. Consequently seller should provide as much detailed and comprehensive product information as possible, including external packing, appearance, application show, function of product and comparison with its similar products. Moreover, information should be presented in multiple ways, such as texts, pictures and videos. And remember that it should be presented in a nice-looking and concise way so that women would prefer to read and be able to understand easily.

Secondly, seller should pay attention to the user's experience when they are communicating with online shopper. Most women like to communicate with seller directly since women consider interpersonal experience as an important element of shopping. With a strong self-respect and self protection awareness, the attitude and language will affect the buying decision directly. Therefore we should have a good attitude and pay attention to the mental feeling brought by the verbal communication. There are several skills as follows: Being flexible in the conversation with customers. In other words, do not rely on an instant messenger to send a fixed auto-reply to your customers, which will only let some sensible shopper think you are handling them in a flow-style. Then try to use some modal particles to soften your tone, it helps to create a good image of seller and reduce disputes as well as offence in the trading market. As we all know saying girly when refusing others is always more acceptable. Last but not the least, use some cute emoticons to show your kind attitude or some emoticons can express your dilemma when you have to turn down some requests.

Thirdly, seller should pay attention to the impact of word-of-mouth evaluation management. Being different from men, women like to start their decision making by asking their friends, and they will pass their buying experience to people around them, which named word-of-mouth. In the process of evaluation management, seller should act as follows: try to get good comment by providing goods with high quality and good service; respond to bad comments immediately and try your best to find out reasons then correct it as soon as possible. As for 
word-of-mouth, seller can set up some reward system to encourage customers to make good comments when the deal is done, which helps to spread the information of goods.

\subsection{Feminine Language Strategy Should Be Adopted in Networking Marketing Communication}

Feminine language strategy could build up an impression of kind and nice in network interpersonal communication. Since people are anonymous and are in non-face-to-face contact, language leads to first impression on the Internet. In order to let customers feel that the speaker is a smile and kind seller with a high quality service, we should try to build up a good image by speaking in feminine language style.

Feminine language strategy conforms to politeness and cooperation policy, and it can raise women's self-esteem to a large extent. Women play a leading role in online shopping. Compared with men, they tend to be more polite and tactful in language using. Meanwhile Taobao style, a gentle and cute language style, fits well in women's language habit and is preferred by women.

Feminine language strategy can also reduce dispute and offence when bargaining or argue take place in the trading market. By using a feminine language, which is kind and gentle, we can reduce bad emotion and helps us to reach an amicable solution when confronted with some tough situation like complaints and refunding.

\section{Summary}

The future of marketing lies in the network, and the future of network marketing lies in women, a huge consumer group. Since women's way of thinking is highly consistent with that on the Internet, the key to success of network marketing to women is to gain insight into women's psychology and market to them according to women's language habit and style. The root cause of prolonged popularity of Taobao style, a language style that emerged in recent years, lies in its substance as a feminine language strategy. Being gentle, girlie and concise, it has a powerful function in interpersonal communication. The polite and gentle image built up by using feminine language in the anonymous network can not only reduce dispute and shorten mental distance between people but also can helps to deal with some tough situation in online trading market like bargaining and refunding. Consequently, feminine language strategy not only can be adored by women, but also can be widely accepted in our daily life. In the meantime, it will bring up a huge mental as well as cultural impact.

\section{Acknowledgments}

This research was financially supported by the China Postdoctoral Science Foundation (Grant NO. 2014M562249)

\section{References}

Chen, Q. L., \& Zheng, X. M. (2008). Women consumerism study review. Commercial Times, (19), 22-26.

Ernst, \& Young. (2007). A new upsurge in Chinese women consumerism is in the making. Business Watch Magazine, (17), 17-20.

Lu, X. W. (2013). Analysis of linguistic characteristics of Taobao style. Journal of Guangdong University of Foreign Studies, (6), $42-47$.

Shi, L. M. (2012). The Pragmatics explain to Taobao style: taking Qin and O as examples. Journal of Lanzhou Institute of Education, (1), 41-45.

Yang, Y. (2014). On the stylistic Characteristics and its development trend of the Taobao-style. Academics, (2), 171-177.

Zhu, W. J. (1992). Sociolinguistic theory. HuNan: Hunan Education Press.

\section{Copyrights}

Copyright for this article is retained by the author(s), with first publication rights granted to the journal.

This is an open-access article distributed under the terms and conditions of the Creative Commons Attribution license (http://creativecommons.org/licenses/by/3.0/). 